\title{
The role of insulin in clustering of serum lipids and blood pressure in children and adolescents
}

\section{The Cardiovascular Risk in Young Finns Study}

\author{
O.T. Raitakari ${ }^{1,2}$, K.V.K.Porkka ${ }^{3}$, T.Rönnemaa ${ }^{4}$, M. Knip ${ }^{5}$, M. Uhari ${ }^{5}$, H. K. Åkerblom ${ }^{6}$, J.S. A. Viikari ${ }^{4}$ \\ ${ }^{1}$ Cardiorespiratory Research Unit, University of Turku, Turku, Finland \\ ${ }^{2}$ Department of Clinical Physiology, University of Turku, Turku, Finland \\ ${ }^{3}$ Third Department of Medicine, University of Turku, Turku, Finland \\ ${ }^{4}$ Department of Medicine, University of Turku, Turku, Finland \\ ${ }^{5}$ Department of Paediatrics, University of Oulu, Oulu, Finland \\ ${ }^{6}$ The Children's Hospital, Second Department of Paediatrics, University of Helsinki, Helsinki, Finland
}

\begin{abstract}
Summary In adults hyperinsulinaemia is associated with an atherogenic risk profile including obesity, low levels of HDL-cholesterol, high levels of triglycerides and elevated blood pressure. To examine these associations in the young we studied the crosssectional relationships of insulin with obesity indices (body mass index, subscapular skinfold thickness), serum lipids and blood pressure in 1,865 children, adolescents and young adults aged 6-24 years. We also used longitudinal data to study the value of a single insulin measurement to predict high risk factor levels and clustering of multiple risk factors after a 6-year follow-up. In cross-sectional analyses the levels of triglycerides, HDL-cholesterol, systolic blood pressure and obesity indices were usually significantly different across the quartiles of fasting insulin in both sexes among children, adolescents and young adults. In general, no associations were seen with total cholesterol or LDL-cholesterol. In prospective
\end{abstract}

analysis elevated baseline insulin was related to the incidence of hypertriglyceridaemia ( $\geq 95$ th percentile) at the follow-up. This relationship persisted even after adjustments for baseline obesity or 6-year change in obesity status. Moreover, baseline insulin concentration was higher in subjects who subsequently showed clustering of high triglycerides, low HDL-cholesterol and high systolic blood pressure levels at the follow-up. We conclude that high fasting insulin levels measured in children and adolescents predict the development of hypertriglyceridaemia years later. In addition, high insulin levels seem to precede the development of a potentially atherogenic risk factor profile including low HDL-cholesterol, high triglycerides and high systolic blood pressure. [Diabetologia (1995) 38: 1042-1050]

Key words Insulin, longitudinal, clustering, children, adolescents, serum lipoproteins, blood pressure.
Dyslipidaemia and high blood pressure often co-exist within the same individual [1-5]. Both of these disorders have been related to obesity and increased plasma insulin levels [6-9]. Lipid abnormalities, elevated blood pressure and high insulin levels are all risk factors for coronary heart disease [10-15]; therefore this cluster of disorders has attracted much atten-

Received: 18 August 1994 and in revised form: 29 December 1994

Corresponding author: Dr. O.T.Raitakari, Cardiorespiratory Research Unit, University of Turku, Kinamyllynkatu 10, FIN-20520 Turku, Finland

Abbreviations: SBP, Systolic blood pressure; DBP, diastolic blood pressure; BMI, body mass index. tion. Recently a hypothesis has been suggested that hyperinsulinaemia and/or insulin resistance may be the key factor that underlies the association of serum lipids and blood pressure [16]. However, this view has also been challenged [17].

While the above-mentioned associations are recognized in adults, only a few studies have been done in children and young adults, none of which have been prospective studies [18]. The available prospective studies in adults have been carried out in two populations: among adults in the San Antonio Heart Study $[19,20]$, and among elderly subjects in eastern Finland [21, 22]. These studies have shown that serum insulin level predicts the development of multiple metabolic disorders including hypertriglyceridaemia, low (HDL)-cholesterol concen- 
tration, hypertension, and non-insulin-dependent diabetes.

The present analysis was carried out to study the associations of insulin with serum lipids, blood pressure and obesity index variables in a representative cohort of children and young adults. We will describe the cross-sectional associations of insulin with these risk indicators, and show results from prospective analysis aimed at testing the hypothesis that high insulin levels precede the changes in lipids and blood pressure.

\section{Subjects and methods}

Population. The Cardiovascular Risk in Young Finns Study is an ongoing large multicentre study on the risk factors of coronary heart disease and their determinants in children, adolescents and young adults. A baseline cross-sectional study was done in 1980. The initial study population consisted of 4,320 children and adolescents aged $3,6,9,12,15$, and 18 years. Of those invited, 3,596 subjects $(83.2 \%)$ participated. Details of the baseline study in 1980 have been published previously [23]. Follow-up studies were carried out in 1983 and 1986 with the same protocol [24]. The loss of subjects was approximately $20 \%$ and $30 \%$ after 3 and 6 years, respectively. Complete data on serum fasting insulin, LDL-cholesterol, total cholesterol, HDL-cholesterol, triglycerides and blood pressure variables from 1980 and 1986 were available on 1,865 subjects, who comprise the cohort in this analysis (age at baseline 6-18 years). Children 3 years of age at baseline were not included due to differences in methodology of blood pressure measurements. The study protocol was approved by the Ethics Committees of each five participating universities (medical schools of Helsinki, Kuopio, Oulu, Tampere, and Turku).

Obesity and blood pressure measurements. Height was measured by a Seca anthropometer (Vogel \& Halke, Hamburg, Germany) and weight by a Seca weighing scale. Body mass in$\operatorname{dex}(\mathrm{BMI})$ was calculated from the formula: weight $\mathrm{kg} / \mathrm{h}$ eight $\mathrm{m}^{2}$. Subscapular skinfolds, expressed as $\mathrm{mm}$, were measured in triplicate from the nondominating arm using a Harpenden skinfolds caliper (Holtain and Bull, British Indicators Ltd., Luton, Beds., UK). Errors in subscapular skinfold measurements were studied according to standard methods [25]. The mean intraobserver error (coefficient of variation) in practice was $4.9 \%$, and the interobserver error during the field study was $14.8 \%$. Measurement errors were of similar magnitude as in other studies [25]. The unadjusted Pearson's correlation coefficient between BMI and subscapular skinfold thickness was 0.76 in 1980 , and 0.72 in 1986 (both, $p<0.001$ ).

Systolic blood pressure (SBP) and diastolic blood pressure (DBP) were measured with a standard mercury sphygmomanometer in 1980, and in 1986 a random zero sphygmomanometer was used. Readings to the nearest even number of $\mathrm{mm} \mathrm{Hg}$ were performed three times on each subject. The mean value of three measurements was used in statistical analysis. Korotkoff's fifth phase was used as the sign of DBP. Details of the methods describing the measuring of blood pressure and anthropometric variables have been presented elsewhere [26, 27 .

Blood samples. For the determination of serum lipoprotein levels, venous blood samples were taken after an overnight fast. Serum samples were stored frozen for no more than 6 months until analysed. All lipid determinations were done in duplicate and in the same laboratory having a reference system with the World Health Organization (WHO) Central Laboratory (Prague, Czech Republic). Standard enzymatic methods were used for serum cholesterol (Boehringer CHOD-PAP kits, Boehringer Mannheim GmbH, Mannheim, Germany) and triglycerides (Boehringer Mannheim $\mathrm{GmbH}$ ). Serum HDL-cholesterol concentration was measured from the serum supernatant after precipitation of (VLDL) and LDL with dextran sulphate and $\mathrm{MgCl}_{2}$ [28]. Details of the methods have been presented elsewhere $[29,30]$. The concentration of LDL-cholesterol was calculated using the Friedewald formula [31]. Serum samples for the determination of insulin were taken after an overnight fast. Sera were separated and stored at $-20^{\circ} \mathrm{C}$ until assayed. Insulin was measured using a modification of the immunoassay method of Herbert et al. [32].

\section{Statistical analysis}

The associations of insulin level with obesity indices, serum lipids and blood pressure were tested with linear regression models. The cross-sectional analyses were carried out after stratification of the study population by age and sex. In 1980, two age groups were formed: children (6-12 years) and adolescents (15-18 years). In 1986, three age groups were formed: children (12 years), adolescents (15-18 years) and young adults (21-24 years). Clustering of risk factors was studied by comparing the observed number of subjects with multiple risk factors with the expected number. The expected number was calculated from the assumption of independence, i.e. assuming that risk factors do not occur simultaneously more often than based on their independent occurrences. Clustering was defined as having simultaneously high triglycerides, high SBP and low HDL-cholesterol ( $\geq 75$ th age- and sex-specific percentile for triglycerides and SBP, $\leq 25$ th percentile for HDLcholesterol). The significance of the difference between the observed and expected rates was tested with the chi-square test. The independent effects of insulin and obesity levels on clustering were studied by logistic regression models, in which insulin and obesity indices were independent variables. In these analyses BMI and subscapular skinfold thickness, as well as insulin, were modelled as four-class variables (ageand sex-specific quartiles).

Longitudinal data were used to study whether baseline insulin level would predict the incidence of extreme serum lipid or blood pressure values, or the incidence of clustering at the follow-up. Risk factor values were defined as extreme, if they were at or above the age- and sex-specific 95th percentile at the follow-up ( $\leq 5$ th percentile for HDL-cholesterol). The definition of clustering was similar as in the cross-sectional analysis, i.e. simultaneous occurrence of high triglycerides, high SBP and low HDL-cholesterol (at their extreme quartiles: highest for triglycerides and SBP, and lowest for HDLcholesterol). Only subjects free of these particular risk factors at baseline were included in the analysis. The effect of baseline insulin level on these end-points was tested by logistic regression models adjusted for baseline BMI and the 6-year change in BMI. All statistical tests were performed with Statistical Analysis System, SAS [33]. Data are shown as mean \pm SD. 
Table 1. Cross-sectional associations of insulin with obesity indices at baseline

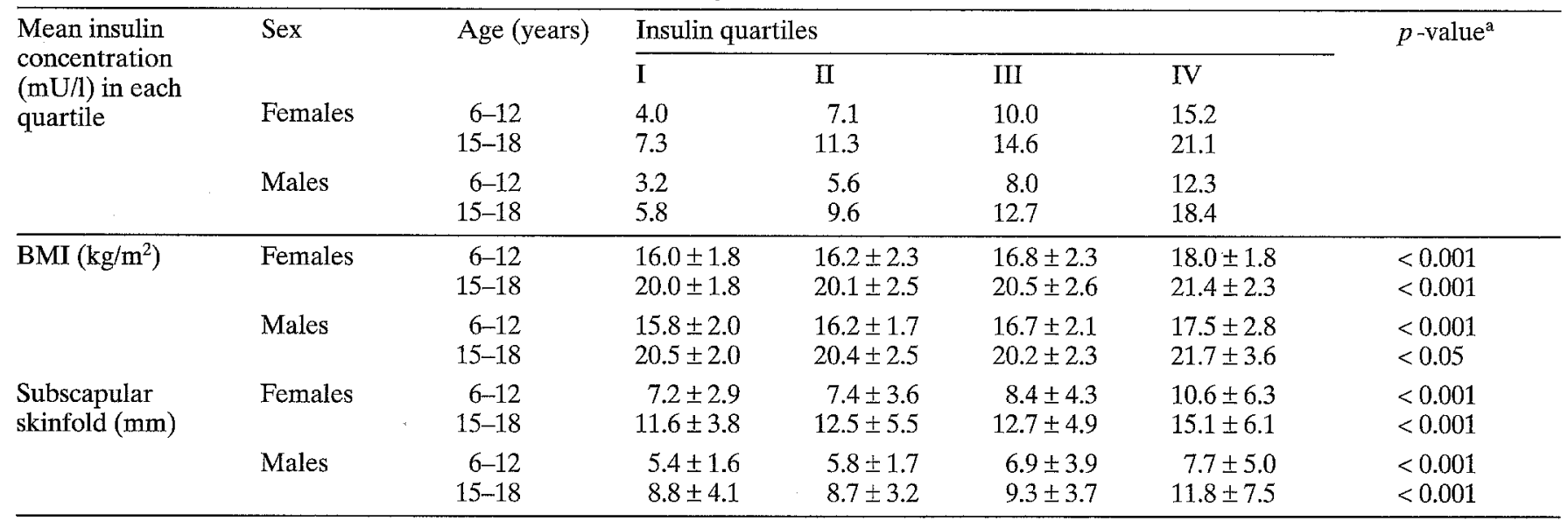

Data are mean $\pm \mathrm{SD}$.

Females, age-group 15-18 years: I = 74; II =84; III = 86;

${ }^{a}$ Linear trend by multiple regression analysis.

No. of subjects by quartiles of insulin: Females, age-group 612 years: $\mathrm{I}=148 ; \mathrm{II}=180 ; \mathrm{III}=156 ; \mathrm{IV}=190$.

$\mathrm{IV}=86$. Males, age-group $6-12$ years: $I=134 ; \quad I I=145$; III $=153 ;$ IV $=167$. Males, age-group $15-18$ years: $I=63$; $\mathrm{II}=62 ; \mathrm{III}=64 ; \mathrm{IV}=73$

\section{Results}

Cross-sectional associations with obesity indices, serum lipids and blood pressure. Table 1 shows the mean values of BMI and subscapular skinfold thickness across the age- and sex-specific quartiles of fasting insulin level at baseline (1980). These obesity indices were strongly and directly associated with insulin level in both sexes, and in both age groups, i.e. children (6-12 years) and adolescents (15-18 years). Similar cross-sectional associations between obesity indices and insulin were seen at follow-up (1986) (Table 2 ) in all age groups, i. e. children (12 years), adolescents (15-18 years) and young adults (21-24 years).

The associations of fasting insulin with serum lipids and blood pressure at baseline (1980) are shown in Table 3. In general, in both sexes among children and adolescents, the levels of triglycerides and SBP became linearly greater from lowest to highest insulin quartile. However, an inverse association was usually seen with HDL-cholesterol levels. No associations were seen between LDL-cholesterol or DBP and insulin levels. In young males ( $6-12$ years), a weak, but significant $(p<0.05)$ inverse association was seen between total cholesterol concentration and insulin level.

The cross-sectional associations of insulin and other risk markers at the follow-up (1986) are shown in Table 4. Again, among both sexes and in nearly all age groups, the levels of triglycerides and SBP were directly associated with the level of insulin, whereas an inverse association was seen between HDL-cholesterol and insulin levels. In addition, a direct association was seen between DBP and insulin level among females in two age groups (15-18 and 21-24 years), and among males in the youngest age group (612 years).

Since triglycerides, HDL-cholesterol and blood pressure levels are known to associate with obesity indices [34], the $p$-values shown in Tables 3 and 4 were adjusted for BMI (the results were identical after adjustment for subscapular skinfold thickness). When all age groups where pooled together, the results remained essentially the same both at the baseline and at the follow-up: in both sexes triglycerides and SBP were directly, and HDL-cholesterol inversely, associated with the insulin level.

Clustering of risk factors. According to data in Tables 3 and 4 increased insulin concentrations were most consistently related to high triglycerides and low HDL-cholesterol levels, as well as to elevated SBP. Next we assessed whether these three factors showed significant clustering in the study population. At baseline, there were 75 subjects $(4.0 \%)$ having all these three risk factors in the extreme ageand sex-specific quartiles ( $\geq 75$ th percentile for triglycerides and SBP, $\leq 25$ th percentile for HDL-cholesterol). The expected proportion would have been $1.6 \%\left(=0.25^{3}\right)$, i. e. when assuming no clustering between the study variables. Chi-square test between the observed and expected rates did not support the assumption of independence $\left(\chi^{2}=20.9, d f=1\right.$, $p<0.001$ ), and thus indicated significant clustering between these three variables. Clustering was of similar magnitude among females and males, and at various ages, data not shown.

The effect of insulin level on clustering of these three risk factors in 1980 is shown in Figure 1. The number of subjects with all three risk factors became greater across the quartiles of insulin. The independent effect of insulin level on clustering was tested with a logistic regression model adjusted for BMI and subscapular skinfold thickness. According to the 
Table 2. Cross-sectional associations of insulin with obesity indices at follow-up

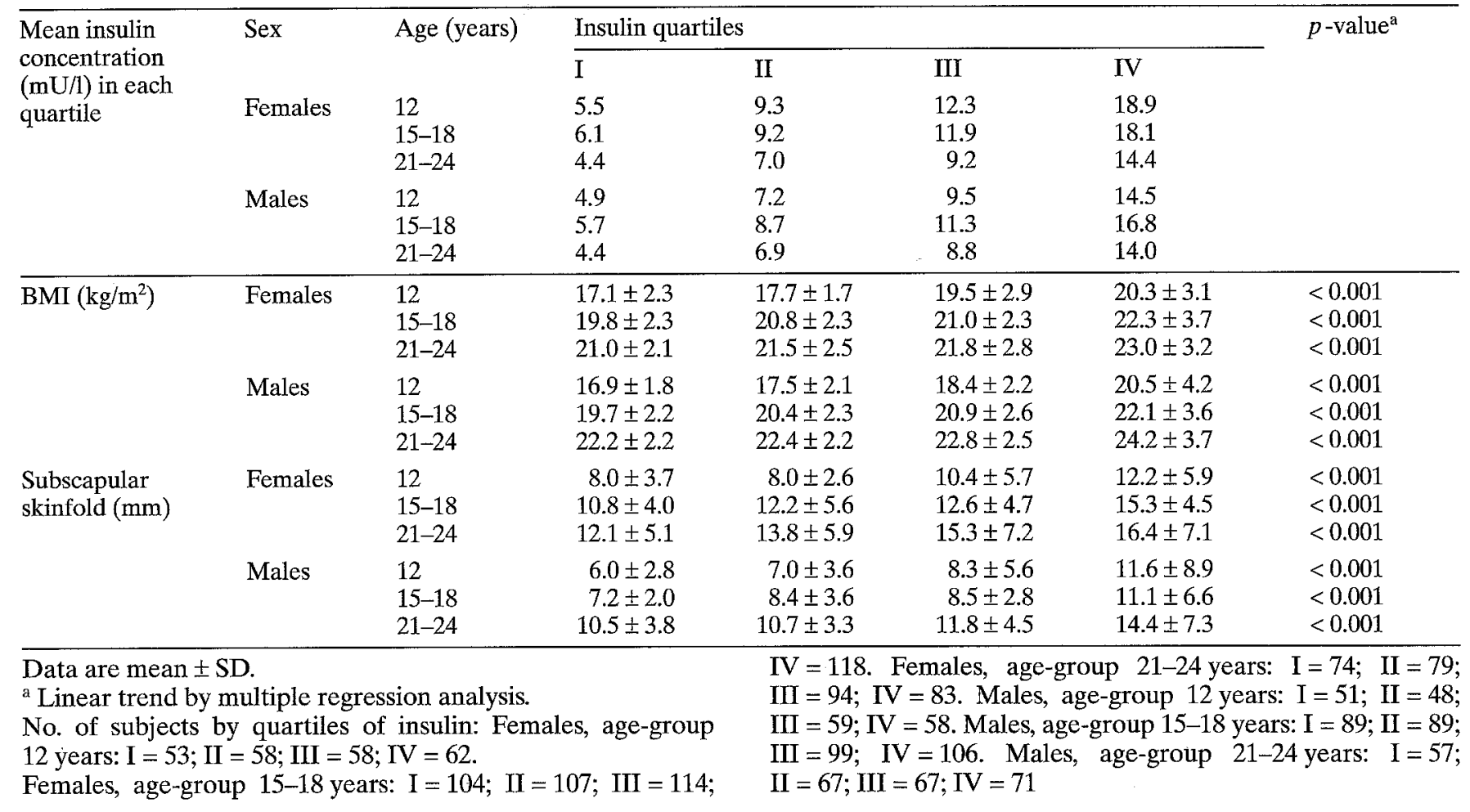

Table 3. Cross-sectional associations of insulin with serum lipids and blood pressure at baseline

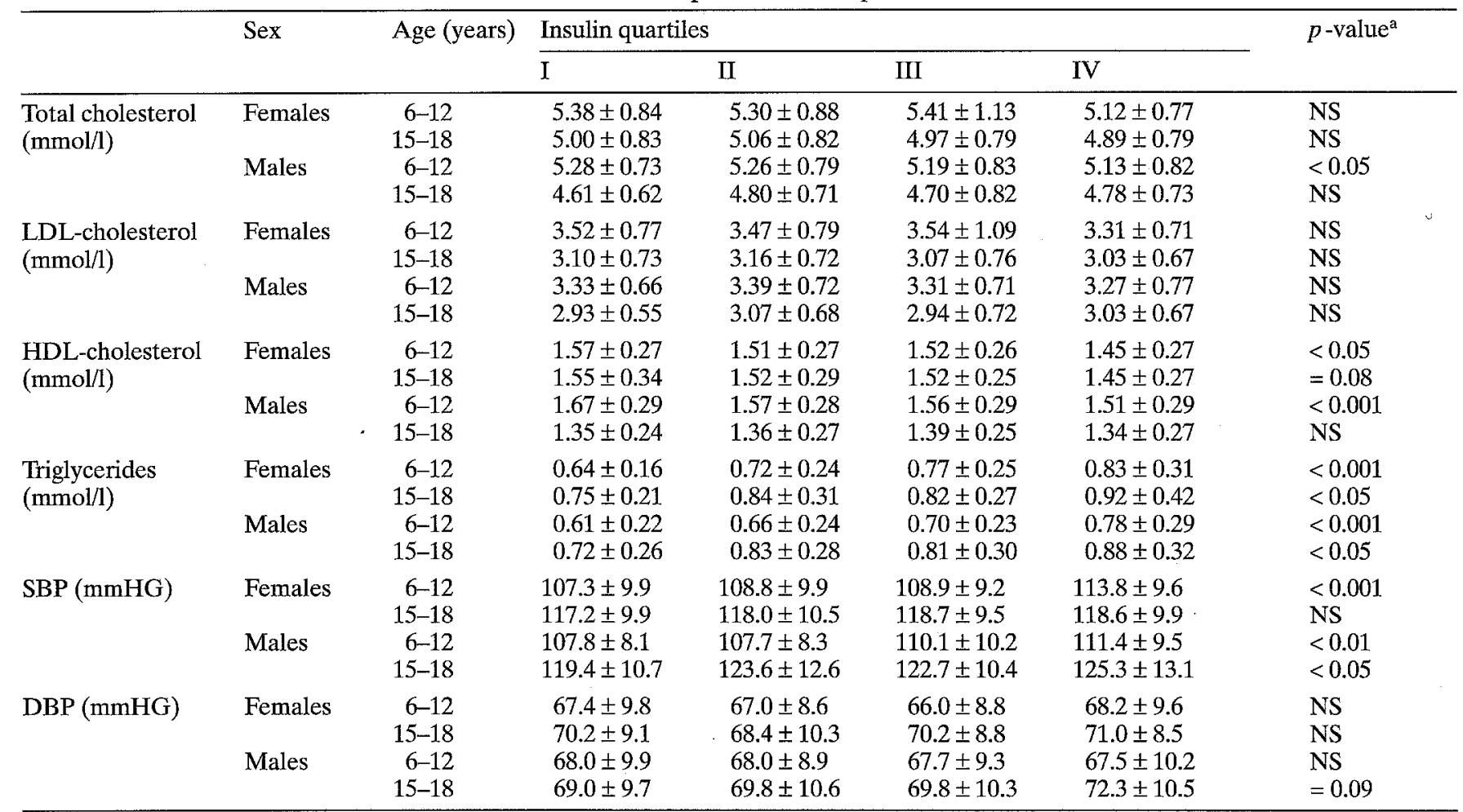

Data are mean \pm SD.

${ }^{a}$ Linear trend by multiple regression analysis adjusted for BMI.

No. of subjects by quartiles of insulin: Females, age-group $6-$ 12 years: $\mathrm{I}=148 ; \mathrm{II}=180 ; \mathrm{III}=156 ; \mathrm{IV}=190$.
Females, age-group $15-18$ years: $\mathrm{I}=74 ; \mathrm{II}=84 ; \mathrm{III}=86$; IV $=86$. Males, age-group $6-12$ years: $I=134 ; \quad I I=145$; $\mathrm{III}=153 ; \mathrm{IV}=167$. Males, age-group $15-18$ years: $\mathrm{I}=63$; $\mathrm{II}=62 ; \mathrm{III}=64 ; \mathrm{IV}=73$ 
Table 4. Cross-sectional associations of insulin with serum lipids and blood pressure at follow up

\begin{tabular}{|c|c|c|c|c|c|c|c|}
\hline & \multirow[t]{2}{*}{ Sex } & \multirow[t]{2}{*}{ Age (years) } & \multicolumn{4}{|c|}{ Insulin quartiles } & \multirow[t]{2}{*}{$p$-value } \\
\hline & & & I & II & III & IV & \\
\hline $\begin{array}{l}\text { Total cholesterol } \\
(\mathrm{mmol} / \mathrm{l})\end{array}$ & $\begin{array}{l}\text { Females } \\
\text { Males }\end{array}$ & $\begin{array}{l}12 \\
15-18 \\
21-24 \\
12 \\
15-18 \\
21-24\end{array}$ & $\begin{array}{l}5.03 \pm 0.72 \\
4.87 \pm 0.94 \\
5.11 \pm 0.89 \\
4.97 \pm 0.88 \\
4.32 \pm 0.67 \\
4.73 \pm 0.84\end{array}$ & $\begin{array}{l}4.79 \pm 0.68 \\
4.75 \pm 0.79 \\
4.85 \pm 0.82 \\
4.89 \pm 0.72 \\
4.29 \pm 0.95 \\
4.75 \pm 0.74\end{array}$ & $\begin{array}{l}4.75 \pm 0.79 \\
4.75 \pm 1.01 \\
5.07 \pm 0.84 \\
4.74 \pm 0.88 \\
4.39 \pm 0.90 \\
4.78 \pm 0.95\end{array}$ & $\begin{array}{l}4.91 \pm 1.25 \\
4.87 \pm 1.04 \\
4.83 \pm 0.91 \\
5.00 \pm 0.78 \\
4.53 \pm 0.94 \\
4.86 \pm 0.95\end{array}$ & $\begin{array}{l}\text { NS } \\
\text { NS } \\
\text { NS } \\
\text { NS } \\
\text { NS } \\
\text { NS }\end{array}$ \\
\hline $\begin{array}{l}\text { LDL-cholesterol } \\
(\mathrm{mmol} / \mathrm{l})\end{array}$ & $\begin{array}{l}\text { Females } \\
\text { Males }\end{array}$ & $\begin{array}{l}12 \\
15-18 \\
21-24 \\
12 \\
15-18 \\
21-24\end{array}$ & $\begin{array}{l}3.20 \pm 0.67 \\
2.99 \pm 0.80 \\
3.16 \pm 0.68 \\
3.15 \pm 0.83 \\
2.61 \pm 0.64 \\
2.95 \pm 0.80\end{array}$ & $\begin{array}{l}2.98 \pm 0.64 \\
2.91 \pm 0.72 \\
2.94 \pm 0.70 \\
3.07 \pm 0.65 \\
2.63 \pm 0.90 \\
3.00 \pm 0.72\end{array}$ & $\begin{array}{l}2.85 \pm 0.71 \\
2.91 \pm 0.94 \\
3.06 \pm 0.78 \\
2.91 \pm 0.76 \\
2.68 \pm 0.83 \\
2.94 \pm 0.85\end{array}$ & $\begin{array}{l}3.06 \pm 1.15 \\
2.95 \pm 1.02 \\
2.90 \pm 0.82 \\
3.13 \pm 0.73 \\
2.80 \pm 0.91 \\
3.03 \pm 0.91\end{array}$ & $\begin{array}{l}\text { NS } \\
\text { NS } \\
<0.05 \\
\text { NS } \\
\text { NS } \\
\text { NS }\end{array}$ \\
\hline $\begin{array}{l}\text { HDL-cholesterol } \\
(\mathrm{mmol} / \mathrm{l})\end{array}$ & $\begin{array}{l}\text { Females } \\
\text { Males }\end{array}$ & $\begin{array}{l}12 \\
15-18 \\
21-24 \\
12 \\
15--18 \\
21-24\end{array}$ & $\begin{array}{l}1.48 \pm 0.24 \\
1.53 \pm 0.29 \\
1.60 \pm 0.41 \\
1.54 \pm 0.27 \\
1.36 \pm 0.25 \\
1.41 \pm 0.25\end{array}$ & $\begin{array}{l}1.45 \pm 0.25 \\
1.46 \pm 0.25 \\
1.52 \pm 0.27 \\
1.51 \pm 0.26 \\
1.27 \pm 0.21 \\
1.34 \pm 0.24\end{array}$ & $\begin{array}{l}1.49 \pm 0.23 \\
1.44 \pm 0.24 \\
1.60 \pm 0.27 \\
1.49 \pm 0.31 \\
1.32 \pm 0.20 \\
1.38 \pm 0.29\end{array}$ & $\begin{array}{l}1.37 \pm 0.21 \\
1.45 \pm 0.24 \\
1.48 \pm 0.28 \\
1.44 \pm 0.29 \\
1.27 \pm 0.21 \\
1.27 \pm 0.23\end{array}$ & $\begin{array}{l}\text { NS } \\
=0.09 \\
<0.05 \\
\text { NS } \\
<0.001 \\
<0.05\end{array}$ \\
\hline $\begin{array}{l}\text { Triglycerides } \\
(\mathrm{mmol} / \mathrm{l})\end{array}$ & Females & $\begin{array}{l}12 \\
15-18 \\
21-24\end{array}$ & $\begin{array}{l}0.78 \pm 0.25 \\
0.77 \pm 0.27 \\
0.77 \pm 0.25\end{array}$ & $\begin{array}{l}0.79 \pm 0.25 \\
0.85 \pm 0.35 \\
0.85 \pm 0.31\end{array}$ & $\begin{array}{l}0.90 \pm 0.30 \\
0.89 \pm 0.31 \\
0.90 \pm 0.31\end{array}$ & $\begin{array}{l}1.06 \pm 0.41 \\
1.02 \pm 0.46 \\
1.00 \pm 0.41\end{array}$ & $\begin{array}{l}<0.001 \\
<0.001 \\
<0.001\end{array}$ \\
\hline & Males & $\begin{array}{l}12 \\
15-18 \\
21-24\end{array}$ & $\begin{array}{l}0.63 \pm 0.17 \\
0.77 \pm 0.33 \\
0.83 \pm 0.31\end{array}$ & $\begin{array}{l}0.70 \pm 0.23 \\
0.85 \pm 0.42 \\
0.89 \pm 0.40\end{array}$ & $\begin{array}{l}0.74 \pm 0.24 \\
0.84 \pm 0.27 \\
1.01 \pm 0.59\end{array}$ & $\begin{array}{l}0.95 \pm 0.29 \\
1.01 \pm 0.41 \\
1.22 \pm 0.75\end{array}$ & $\begin{array}{l}<0.001 \\
<0.01 \\
<0.001\end{array}$ \\
\hline $\mathrm{SBP}(\mathrm{mmHG})$ & Females & $\begin{array}{l}12 \\
15-18 \\
21-24\end{array}$ & $\begin{array}{l}106.7 \pm 9.2 \\
109.3 \pm 9.5 \\
115.0 \pm 10.4\end{array}$ & $\begin{array}{l}108.0 \pm 8.4 \\
113.7 \pm 9.7 \\
116.1 \pm 10.2\end{array}$ & $\begin{array}{l}109.1 \pm 8.3 \\
114.3 \pm 10.1 \\
117.8 \pm 10.2\end{array}$ & $\begin{array}{l}112.5 \pm 9.9 \\
117.3 \pm 10.3 \\
118.5 \pm 13.1\end{array}$ & $\begin{array}{l}\text { NS } \\
<0.001 \\
=0.05\end{array}$ \\
\hline & Males & $\begin{array}{l}12 \\
15-18 \\
21-24\end{array}$ & $\begin{array}{l}104.3 \pm 8.1 \\
118.3 \pm 11.8 \\
126.0 \pm 12.6\end{array}$ & $\begin{array}{l}105.0 \pm 8.2 \\
118.6 \pm 10.3 \\
126.6 \pm 9.7\end{array}$ & $\begin{array}{l}107.6 \pm 6.2 \\
122.4 \pm 12.4 \\
127.7 \pm 9.2\end{array}$ & $\begin{array}{l}112.0 \pm 10.9 \\
125.1 \pm 10.6 \\
130.5 \pm 10.2\end{array}$ & $\begin{array}{l}<0.01 \\
<0.01 \\
<0.05\end{array}$ \\
\hline $\mathrm{DBP}(\mathrm{mmHG})$ & Females & $\begin{array}{l}12 \\
15-18 \\
21-24\end{array}$ & $\begin{array}{l}61.0 \pm 9.1 \\
63.5 \pm 9.3 \\
68.0 \pm 9.0\end{array}$ & $\begin{array}{l}62.7 \pm 8.1 \\
67.0 \pm 7.9 \\
68.7 \pm 9.8\end{array}$ & $\begin{array}{l}60.5 \pm 10.4 \\
65.7 \pm 8.3 \\
70.2 \pm 9.1\end{array}$ & $\begin{array}{l}64.3 \pm 7.7 \\
68.4 \pm 9.1 \\
71.9 \pm 8.7\end{array}$ & $\begin{array}{l}\text { NS } \\
<0.01 \\
<0.01\end{array}$ \\
\hline & Males & $\begin{array}{l}12 \\
15-18 \\
21-24\end{array}$ & $\begin{array}{l}56.5 \pm 9.6 \\
66.0 \pm 9.5 \\
72.2 \pm 11.4\end{array}$ & $\begin{array}{l}58.0 \pm 9.9 \\
66.2 \pm 9.8 \\
72.3 \pm 10.3\end{array}$ & $\begin{array}{l}60.7 \pm 8.7 \\
67.3 \pm 9.3 \\
72.5 \pm 9.7\end{array}$ & $\begin{array}{l}62.4 \pm 8.0 \\
68.9 \pm 9.1 \\
74.2 \pm 10.5\end{array}$ & $\begin{array}{l}<0.01 \\
\text { NS } \\
\text { NS }\end{array}$ \\
\hline
\end{tabular}

Data are mean $\pm S D$.

${ }^{a}$ Linear trend by multiple regression analysis adjusted for BMI Number of subjects by quartiles of insulin: Females, age-group 12 years: $\mathrm{I}=53 ; \mathrm{II}=58 ; \mathrm{III}=58 ; \mathrm{IV}=62$.

Females, age-group 15-18 years: $\mathrm{I}=104$; II $=107$; III $=114$; IV $=118$. Females, age-group $21-24$ years: $\mathrm{I}=74 ; \mathrm{II}=79$;

logistic model insulin and subscapular skinfold thickness levels were both independently associated with clustering, but the effect of subscapular skinfold thickness became non-significant when BMI was also introduced to the model. In this logistic model with insulin, BMI and subscapular skinfold thickness as independent variables the odds ratio for trend for the effect of insulin was 1.60 (95\% confidence interval 1.24-2.06; $p<0.001$ ), for the effect of BMI: 1.79 $(1.29-2.47 ; p<0.001)$, and for the effect of subscapular skinfold thickness: $1.10(0.81-1.47$; NS).

When clustering was studied at the follow-up the results were essentially similar. There were 71 subjects $(3.8 \%)$ having all three risk factors in 1986 (observed vs expected: $\left.\chi^{2}=20.9, d f=1: p<0.001\right)$. In
$\mathrm{III}=94 ; \mathrm{IV}=83$. Males, age-group 12 years: $\mathrm{I}=51 ; \mathrm{II}=48$; $\mathrm{III}=59 ; \mathrm{IV}=58$. Males, age-group $15-18$ years: $\mathrm{I}=89 ; \mathrm{II}=89$; $\mathrm{III}=99 ; \quad \mathrm{IV}=106$. Males, age-group $21-24$ years: $\mathrm{I}=57$; $\mathrm{II}=67 ; \mathrm{II}=67 ; \mathrm{IV}=71$

the logistic model adjusted for both obesity indices, the odds ratio for trend for the effect of insulin was $1.72(1.30-2.26 ; p<0.001)$, for the effect of BMI: $2.36(1.65-3.38 ; p<0.001)$, and for the effect of subscapular skinfold thickness 0.98 (0.73-1.33; NS).

Prospective analyses. The relationships of baseline insulin level to the incidence of various end-points are shown in Table 5. The proportion of subjects who developed hypertriglyceridaemia at the follow-up (triglyceride concentration $\geq 95$ th percentile) became greater across baseline quartiles of insulin. Furthermore, subjects presenting clustering of risk factors at the follow-up had higher baseline insulin levels. After adjustments for baseline BMI and 6-year 


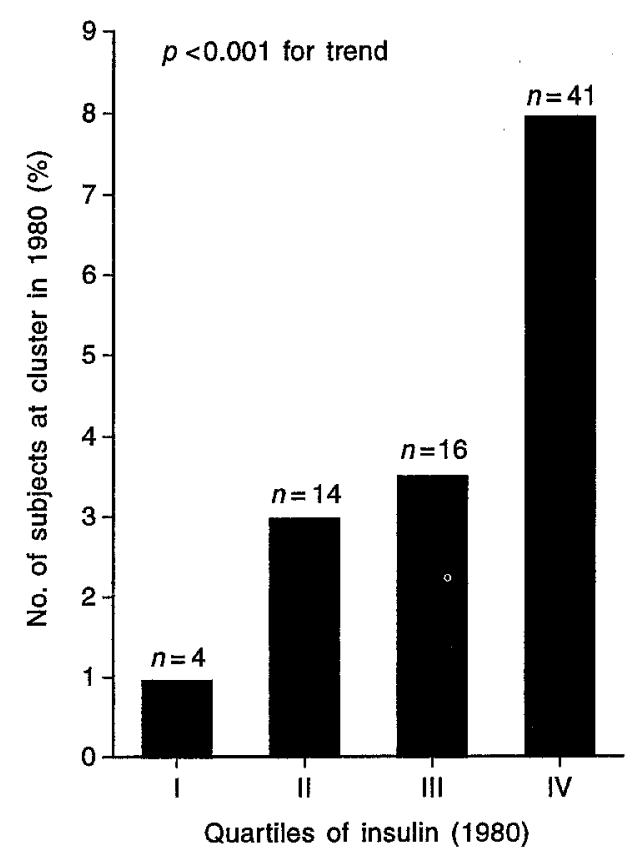

Fig. 1. Proportion (\%) of subjects at cluster in 1980 (baseline), i. e. with high triglycerides ( $\geq 75$ th percentile), low HDL-cholesterol ( $\leq 25$ th percentile) and high SBP ( $\geq 75$ th percentile) across quartiles of insulin. Odds ratio for trend for the effect of insulin: 1.60 (95\% confidence interval 1.24 to 2.06 ; $p<0.001$ ), adjusted for BMI and subscapular skinfold thickness

change in BMI, high baseline insulin level remained significantly associated with the incidence of hypertriglyceridaemia and clustering at the follow-up. When the adjustments were made, in addition to BMI, also with subscapular skinfold thickness and the 6-year change in subscapular skinfold thickness, the effects of insulin on the incidence of hypertriglyceridaemia and clustering remained statistically significant (both $p<0.05$ ).

We also looked at the parallel models to see if the baseline triglyceride or obesity levels would predict the incidence of hyperinsulinaemia (i.e. testing for causality in the opposite direction). The incidence of hyperinsulinaemia at the follow-up did not differ significantly across quartiles of baseline triglyceride level (data not shown). On the contrary, the incidence of hyperinsulinaemia became greater across the quartiles of baseline obesity levels. The incidence of hyperinsulinaemia across quartiles of baseline BMI was: $\mathrm{I}=3.5 \%, \mathrm{II}=3.1 \%$, III $=4.7 \%$, and $\mathrm{IV}=8.3 \%$. Odds ratio for trend was $1.42(1.16-1.73 ; p<0.001)$. The incidence of hyperinsulinaemia across quartiles of baseline subscapular skinfold thickness was: $\mathrm{I}=4.4 \%, \mathrm{II}=3.6 \%, \quad \mathrm{III}=3.9 \%$, and $\mathrm{IV}=7.5 \%$. Odds ratio for trend was $1.24(1.02-1.51 ; p<0.05)$. When both obesity indices where included in the same logistic regression model, the effect of BMI remained significant $(p<0.01)$, but the effect of subscapular skinfold thickness became insignificant $(p=0.89)$.

\section{Discussion}

The existence of an insulin resistance syndrome requires that the components of this syndrome occur together more often than would be expected by chance alone, and that a common aetiologic factor is associated with this clustering. We found that high insulin concentration was associated with high levels of triglycerides, low levels of HDL-cholesterol and elevated $S B P$, and that these three conditions showed significant clustering in the study population. Moreover, this clustering was associated with increased insulin levels independent of obesity. Thus, our results support the idea that a specific syndrome with multiple metabolic disorders exists already in the young. Furthermore, our data show that the associations between insulin, triglycerides, HDL-cholesterol and SBP are not only limited to high levels of these factors, but are in fact present within the normal ranges of serum lipid, blood pressure and insulin levels. This implies that the relationship of insulin concentration with serum lipid and blood pressure profile are fundamental metabolic functions. Therefore, the insulin resistance syndrome may reflect one end of a continuum of normal physiological links rather than a clear-cut syndrome [9]. In the present study high insulin concentration was not associated with high total cholesterol or high LDL-cholesterol concentrations. This result is in concert with previous findings suggesting that hypercholesterolaemia is not an integral factor of the metabolic syndrome $[19,35]$.

Most of the studies linking hyperinsulinaemia and/ or insulin resistance to changes in serum lipids and blood pressure have been cross-sectional and conducted in adult populations $[6,9,16,36]$. Our group has previously studied the cross-sectional relationships between insulin and other risk factors in this population by correlation analyses $[37,38]$. The cross-sectional results in this study are in line with these previous findings. In this study we also used longitudinal data that had been gathered during the 6year follow-up. Earlier prospective analyses of the insulin resistance syndrome are few and none of them have included children or adolescents. At present it is still not certain whether hyperinsulinaemia is causally associated with worsening of the lipid or blood pressure profile [39]. We found that high insulin level measured 6 years earlier in children and adolescents was predictive of hypertriglyceridaemia at the follow-up. Furthermore, the opposite did not occur, i.e. baseline triglyceride level was not associated with later hyperinsulinaemia. This finding supports the idea that insulin has a direct regulatory effect on triglyceride concentrations. Earlier studies showing that lowering of triglyceride concentration with drugs does not improve insulin sensitivity also suggest that hypertriglyceridaemia seems to be a consequence rather than a cause of insulin resistance [40,41]. 
Table 5. Incidence (\%) of various end-points according to age and sex-specific quartiles of insulin at baseline

\begin{tabular}{|c|c|c|c|c|c|c|c|c|}
\hline \multirow[t]{2}{*}{ End-point at follow-up } & \multirow{2}{*}{$\begin{array}{l}\text { Incidence \% } \\
\text { (incident } \\
\text { cases/others }^{\mathrm{c}}\end{array}$} & \multicolumn{4}{|c|}{ Baseline insulin quartile } & \multirow{2}{*}{$\begin{array}{l}\text { Odds ratio }{ }^{d} \\
{[95 \% \mathrm{CI}]}\end{array}$} & \multirow{2}{*}{$\begin{array}{l}\text { Odds ratio }^{\mathrm{e}} \\
{[95 \% \mathrm{CI}]}\end{array}$} & \multirow{2}{*}{$\begin{array}{l}\text { Odds ratio } \\
{[95 \% \mathrm{CI}]}\end{array}$} \\
\hline & & I & II & III & IV & & & \\
\hline High BMI & $3.0(53 / 1723)$ & 2.6 & 1.9 & 3.2 & 4.2 & $1.23[0.96-1.58]$ & - & - \\
\hline High Total-C & $3.5(62 / 1715)$ & 4.5 & 3.4 & 2.5 & 3.6 & $0.92[0.73-1.15]$ & - & - \\
\hline High LDL-C & $3.4(60 / 1716)$ & 4.3 & 3.2 & 2.3 & 3.8 & $0.95[0.76-1.19]$ & - & - \\
\hline Low HDL-C & $4.4(78 / 1701)$ & 2.9 & 5.4 & 4.1 & 5.0 & $1.13[0.92-1.38]$ & - & - \\
\hline High DBP & $5.1(91 / 1701)$ & 5.8 & 4.2 & 4.5 & 5.9 & $1.03[0.85-1.24]$ & - & - \\
\hline Clustering $\mathrm{g}$ & $3.5(63 / 1727)$ & 1.9 & 2.8 & 3.4 & 5.7 & $1.44^{\mathrm{b}}[1.14-1.84]$ & $1.38^{\mathrm{b}}[1.08-1.76]$ & $1.30^{\mathrm{a}}[1.02-1.66]$ \\
\hline
\end{tabular}

${ }^{\mathrm{a}} p<0.05 ;{ }^{\mathrm{b}} p<0.01$.

c Subjects free of the particular risk factor at baseline. ${ }^{\mathrm{d}}$ Odds ratio for trend, non-adjusted. ${ }^{\mathrm{e}}$ Odds ratio for trend adjusted for baseline BMI. ${ }^{\mathrm{f}}$ Odds ratio for trend adjusted for baseline

BMI and 6-year change in BMI. $\mathrm{g}$ Three risk factors (HDLcholesterol, triglycerides, SBP) at or above the age- and sexspecific 75 th percentile (lowest quartile used for HDL-cholesterol)

Although insulin did not predict the incidence of low levels of HDL-cholesterol or high blood pressure, it was significantly associated with clustering of low HDL-cholesterol, high triglycerides and high SBP at follow-up (all three risk factors at their extreme quartiles). Therefore, our results suggest that hyperinsulinaemia may be causally related with the deterioration of lipid and blood pressure profile. Earlier prospective evidence about the role of insulin in the development of multiple metabolic disorders comes from two adult population, namely the San Antonio Heart Study and the study of elderly subjects in eastern Finland. These data have shown that elevation in insulin concentration precedes the development of high levels of triglycerides and low levels of HDL-cholesterol [19-22]. The evidence that hyperinsulinaemia would precede the development of elevated blood pressure is not so consistent. In the above-mentioned analyses from the San Antonio Heart Study the association of insulin and blood pressure elevation was only seen in certain subpopulations, such as in lean subjects [19] or subjects not on antihypertensive medication [20], but not in the whole study population.

There are several mechanisms that would explain the cause-and-effect relationship of insulin and other risk factors. Hyperinsulinaemia is associated with increased visceral fat and abundant availability of nonesterified fatty acids from fat tissue may lead to increased production of VLDL by the liver [42]. In addition, insulin itself may enhance the synthesis of hepatic VLDL and thereby contribute to high levels of triglycerides [16, 43]. Low HDL-cholesterol concentration may result from increased rate of apolipoprotein $\mathrm{AI} / \mathrm{HDL}$ degradation seen in hyperinsulinaemia and insulin resistance [44], or alternatively it may be secondary to elevations in triglyceride concentration [45]. Hyperinsulinaemia or insulin resistance may raise blood pressure by increasing the activity of the sympathetic nervous system [46], or by promoting the renal reabsorption of sodium [47]. Also, cellular deficiency of insulin may alter calcium metabolism which leads to the increase in vascular smooth muscle tone [48]. However, contradictory data also exist: possible mechanisms have been suggested that consider elevations in VLDL-triglycerides or blood pressure as causes of hyperinsulinaemia. Infusion of lipids has been shown to impair insulin action and thereby stimulate insulin secretion [49]. Julius et al. [50] have suggested that blood pressure elevation may induce loss of capillary vessels in skeletal muscle, and that this would promote local insulin resistance and subsequently lead to compensatory hyperinsulinaemia [50]. Thus, the specific mechanisms involved in the pathogenesis of the metabolic syndrome are not established.

One limitation of this study is that we measured only fasting insulin levels which are only a crude measure of insulin resistance. Therefore, fasting insulin levels may underestimate the strength of association between insulin resistance and other risk factors. Another limitation to our study is that we did not have a validated measure, such as waist to hip ratio, to indicate unfavourable fat distribution. Subscapular skinfold thickness was included in this study, since it has been used earlier as a measure of truncal or centralized fat distribution in children of the Bogalusa Heart Study [51]. In our study, subscapular skinfold thickness was cross-sectionally associated with a clustering of risk factors. Furthermore, it was prospectively associated with the incidence of hyperinsulinaemia suggesting that obesity estimated by measuring the subscapular skinfold thickness is a risk factor for the development of hyperinsulinaemia. However, these effects disappeared after BMI was also included in the statistical models, i.e. BMI was a stronger predictor of clustering or the incidence of hyperinsulinaemia compared to subscapular skinfold thickness.

In summary, bearing the limitation in mind that even prospective data cannot prove causality, these 
data demonstrate that high fasting insulin concentrations measured in children and adolescents are predictive of the development of hypertriglyceridaemia years later. Furthermore, our results suggest that hyperinsulinaemia precedes unfavourable changes in the lipid and blood pressure profile including clustering of high triglycerides, low HDL-cholesterol and high SBP.

Acknowledgements. This study was financially supported by the Academy of Finland, the Emil Aaltonen Foundation, the Foundation of the Finnish Cardiac Society, the Ida Montin Foundation, the Juho Vainio Foundation, the Sigrid Juselius Foundation and the Foundation of Turku University. The authors thank Professor K. Pyörälä and Dr. J.Knuuti for their comments on the manuscript.

\section{References}

1. Kotchen JM, Kothchen TA, Guthrie GP, Cottrill CM, McKean HE (1980) Correlates of adolescent blood pressure at five-year follow-up. Hypertension 2 [Suppl I]: I124-I-129

2. Salonen JT, Puska P, Kottke TE, Heinonen OP (1981) Coronary risk factor clustering patterns in Eastern Finland. Int J Epidemiol 10: 203-210

3. Criqui MH, Cowan LD, Heiss G, Haskell WL, Laskarzewski PM, Chambless LE (1986) Frequency and clustering of nonlipid coronary risk factors in dyslipoproteinemia. The Lipid Research Clinics Program Prevalence Study. Circulation 73 [Suppl I]: 40-50

4. Williams RR, Hunt SC, Hopkins PN et al. (1988) Familial dyslipidemic hypertension. Evidence from $58 \mathrm{Utah}$ families for a syndrome present in approximately $12 \%$ of patients with essential hypertension. JAMA 259: 3579-3586

5. Bønaa KH, Thelle DS (1991) Association between blood pressure and serum lipids in a population. The Troms $\varnothing$ Study. Circulation 83: 1305-1314

6. Modan M, Halkin H, Almog S et al. (1985) Hyperinsulinemia: a link between hypertension, obesity and glucose intolerance. J Clin Invest 75: 809-817

7. Fuh M M-T, Shieh S-M, Wu D-A, Chen Y-D I, Reaven GM (1987) Abnormalities of carbohydrate and lipid metabolism in patients with hypertension. Arch Intern Med 147: 1035-1038

8. Manolio TA, Savage PJ, Burke GI et al. (1990) Association of fasting insulin with blood pressure and lipids in young adults. The CARDIA Study. Arteriosclerosis 10: 430-436

9. Ferrannini E, Haffner SM, Mitchell BD, Stern MP (1991) Hyperinsulinaemia: the key feature of a cardiovascular and metabolic syndrome. Diabetologia 34: 416-422

10. Kannel WB (1977) Importance of hypertension as a major risk factor in cardiovascular disease. In: Genest J, Koiw E, Kuchel O (eds) Hypertension. McGraw-Hill, New York, pp 888-910

11. Welborn TA, Wearne K (1979) Coronary heart disease incidence and cardiovascular mortality in Busselton with reference to glucose and insulin concentrations. Diabetes Care 2: $154-160$

12. Ducimetiere P, Eschwege E, Papoz L, Richard JL, Claude JR, Rosselin G (1980) Relationship of plasma insulin levels to the incidence of myocardial infarction and coronary heart disease mortality in a middle-aged population. Diabetologia 19: 205-210
13. Pyörälä K, Savolainen E, Kaukola S, Haapakoski J (1985) Plasma insulin as coronary risk factor: relationships to other risk factors and predictive value during $91 / 2$ year follow-up of the Helsinki Policeman Study population. Acta Med Scand [Suppl] 701: 38-52

14. Brunner D, Weisport J, Meshular N et al. (1987) Relations of serum total cholesterol and high-density lipoprotein cholesterol percentage to the incidence of definite coronary events: twenty-year follow-up of the Donolo-Tel Aviv Prospective Coronary Artery Disease Study. Am J Cardiol 59: 1271-1276

15. Abbott RD, Wilson PW, Kannel WB, Castelli WP (1988) High density cholesterol, total cholesterol screening, and myocardial infarction. The Framingham Study. Arteriosclerosis 8: 207-211

16. Reaven GM (1988) Role of insulin resistance in human disease. Diabetes 37: 1595-1607

17. Jarrett RJ (1992) In defence of insulin: a critique of syndrome X. Lancet 340: 469-471

18. Gidding SS (1993) Relationships between blood pressure and lipids in childhood. Pediatr Clin N Am 40: 41-49

19. Haffner SM, Valdez RA, Hazuda HP, Mitchell BD, Morales PA, Stern MP (1992) Prospective analysis of the insulin-resistance syndrome (Syndrome X). Diabetes 41: 715-722

20. Mitchell BD, Haffner SM, Hazuda HP, Valdez R, Stern MP (1992) The relation between serum insulin levels and 8year changes in lipid, lipoprotein, and blood pressure levels. Am J Epidemiol 136: 12-22

21. Mykkänen L, Kuusisto J, Haffner SM, Pyörälä K, Laakso M (1994) Hyperinsulinemia predicts multiple atherogenic changes in lipoproteins in elderly subjects. Arterioscler Thromb 14: 518-526

22. Mykkänen L, Kuusisto J, Pyörälä K, Laakso M (1993) Cardiovascular disease risk factors as predictors of type 2 (non-insulin-dependent) diabetes mellitus in elderly subjects. Diabetologia 36: 553-559

23. Åkerblom HK, Viikari J, Uhari M et al. (1985) Atherosclerosis precursors in Finnish children and adolescents. I. General description of the cross-sectional study of 1980 , and an account of the children's and families' state of health. Acta Paediatr Scand [Suppl] 318: 49-63

24. Åkerblom HK, Uhari M, Pesonen E et al. (1991) Cardiovascular Risk in Young Finns. Ann Med 23: 35-39

25. Owen GM (1982) Measurement, recording, and assessment of skinfold thickness in childhood and adolescence: report of a small meeting. Am J Clin Nutr 35: 629-638

26. Uhari M, Nuutinen EM, Turtinen J et al. (1991) Blood pressure in children, adolescents and young adults. Ann Med 23: $47-51$

27. Dahlström S, Viikari J, Åkerblom HK et al. (1985) Atherosclerosis precursors in Finnish children and adolescents. II. Height, weight, body mass index, and skinfolds, and their correlation to metabolic variables. Acta Paediatr Scand [Suppl] 318: 65-78

28. Finley PR, Schifman RB, Williams J, Lichti DA (1978) Cholesterol in high density lipoprotein: use of $\mathrm{Mg}^{2+} / \mathrm{dex}-$ tran sulphate in its enzymatic measurement. Clin Chem 24: 931-937

29. Viikari J, Åkerblom HK, Nikkari T et al. (1985) Atherosclerosis precursors in Finnish children and adolescents. IV. Serum lipids in newborns, children and adolescents. Acta Paediatr Scand [Suppl] 318: 103-109

30. Viikari J, Rönnemaa T, Seppänen A et al. (1991) Serum lipids and lipoproteins in children, adolescents and young adults in 1980-1986. Ann Med 23: 53-59

31. Friedewald WT, Levy R, Fredrickson DS (1972) Estimation of the concentration of low-density lipoprotein cholesterol 
in plasma without use of the preparative ultracentrifuge. Clin Chem 18: 499-502

32. Herbert V, Lau KS, Gottlieb CW, Bleicher SJ (1965) Coated charcoal immunoassay of insulin. J Clin Endocrinol Metab 25: 1375-1384

33. SAS Institute Inc. (1988) SAS/STAT User's Guide. Release 6.03. SAS Institute Inc., Cary, NC

34. Hubert HB (1986) The importance of obesity in the development of coronary risk factors and disease: the epidemiologic evidence. Annu Rev Public Health 7: 493-502

35. Karhapää P, Voutilainen E, Kovanen PT, Laakso M (1993) Insulin resistance in familial and nonfamilial hypercholesterolemia. Arterioscler Thromb 13: 41-47

36. Laws A, King AC, Haskell WL, Reaven GM (1991) Relation of fasting plasma insulin concentration to high density lipoprotein cholesterol and triglyceride concentrations in men. Arterioscler Thromb 11: 1636-1642

37. Lautala P, Åkerblom HK, Viikari J et al. (1985) Atherosclerosis precursors in Finnish children and adolescents. VII. Serum immunoreactive insulin. Acta Paediatr Scand [Suppl] 318: 127-133

38. Rönnemaa T, Knip M, Lautala P et al. (1991) Serum insulin and other cardiovascular risk indicators in children, adolescents and young adults. Ann Med 23: 67-72

39. Donahue RP, Skyler JS, Schneiderman B, Prineas RJ (1990) Hyperinsulinemia and elevated blood pressure: cause, confounder or coincidence? Am J Epidemiol 132: 827-836

40. Karhapää P, Uusitupa M, Voutilainen E, Laakso M (1992) Effects of bezafibrate on insulin sensitivity and glucose tolerance in subjects with combined hyperlipidemia. Clin Pharmacol Ther 52: 620-626

41. Riccardi G, Genovese S, Saldalamacchia G et al. (1989) Effects of bezafibrate on insulin secretion and insulin sensitivity in hyperlipidemic patients with and without diabetes. Atherosclerosis 75: 175-181
42. DeFronzo RA, Ferrannini E (1991) Insulin resistance a multifaceted syndrome responsible for NIDDM, obesity, hypertension, dyslipidemia, and atherosclerotic cardiovascular disease. Diabetes Care 14: 173-194

43. Lewis GF, Uffelman KD, Szeto LW, Steiner G (1993) Effects of acute hyperinsulinemia on VLDL triglyceride and VLDL apoB production in normal weight and obese individuals. Diabetes 42: 833-842

44. Golay A, Zech L, Shi M-Z et al. (1987) Role of insulin in regulation of high density lipoprotein metabolism. J Lipid Res 28: 10-18

45. Applebaum-Bowden D, Haffner SM, Wahl PW et al. (1985) Postheparin plasma triglyceride lipases: relationships with very low density lipoprotein triglyceride and high density lipoprotein 2 cholesterol. Arteriosclerosis 5: 273-282

46. Rowe JW, Young JB, Minaker KL, Stevens AL, Pallotta J, Landsberg L (1981) Effect of insulin and glucose infusions on sympathetic nervous system activity in normal man. Diabetes 30: 219-225

47. DeFronzo RA, Cooke C, Andres R, Faloona GR, Davis PJ (1975) The effect of insulin in renal handling of sodium, potassium, calcium, and phosphate in man. J Clin Invest 55: 845-855

48. Standley PR, Bakir MH, Sowers JR (1993) Vascular insulin abnormalities, hypertension, and accelerated atherosclerosis. Am J Kidney Dis 21: 39-46

49. Thiebaud D, DeFronzo RA, Jacot E et al. (1982) Effect of long chain triglyceride infusion on glucose metabolism in man. Metabolism 31: 1128-1136

50. Julius S, Gudbrandsson T, Jamerson K, Tariq Shahab S, Andersson O (1991) The hemodynamic link between insulin resistance and hypertension. J Hypertens 9: 983-986

51. Smoak CG, Burke GL, Webber LS, Harsha DW, Srinivasan SR, Berenson GS (1987) Relation of obesity to clustering of cardiovascular disease risk factors in children and young adults. The Bogalusa Heart Study. Am $\mathbf{J}$ Epidemiol 125: $364-372$ 